\title{
1. Researching routines as strategies: a strategy-as-practice view
}

\section{INTRODUCTION: RESEARCHING ROUTINES AS STRATEGIES}

Over the last decade, we have seen the development of a very persuasive argument for a more careful study of strategy making as being enabled and constrained by prevailing organizational practices (Golsorkhi et al., 2010; Vaara and Whittington, 2012). This stance invites us to re-think several taken-for-granted premises in strategy research (Johnson et al., 2003; Whittington, 2006), as well as how strategy research relates to managerial practice (Melin, 2007). Several major issues still require further theoretical conceptualization and empirical description. We argue that a more detailed analysis of agency as embedded in a web of different practices would advance our understanding of strategy making as relating to, and emerging from, organizational processes (Vaara and Whittington, 2012). This is important for understanding agency in strategizing (Golsorkhi et al., 2010), and offers a way of getting beyond the micro-macro divide that characterizes most strategy research (Johnson et al., 2007). We also see re-considering the practice of thinking as essential for understanding the enactment of organizational practices and routines (Melin, 2007), and that studying strategizing events (Johnson, 2007), especially in relation to strategic renewal (Chakravarthy and Doz, 1992; Floyd et al., 2011) would contribute productively to this research agenda. In this respect, our focus on the management of recurrent creation 'at the edge' provides a good research setting.

As Chapter 1 of our study, we propose to review the current strategy literature on how strategies relate to routines, and in particular on how they emerge from organizational routines, as offering a promising opportunity to develop answers to some open issues in the strategy-as-practice research perspective, as well as to show how a practice perspective on strategies and routines might advance strategy research in general. We identify organizational routines as 'repetitive, recognizable patterns of interdependent action carried out by multiple participants' (Pentland and Feldman, 2008: 235), and thus as particular organizational practices 
(Feldman and Orlikowski, 2011). As discussed in the introduction, we are specifically interested in considering how routine performances are managerially enacted. We see this focus as an interesting way to reconcile strategy-as-practice research, which describes strategizing as a distributed organizational activity, with a description of how management is involved in such strategizing (Golsorkhi et al., 2010). Given our research focus on recurrent creation 'at the edge', we specifically orient our literature review towards strategies and routines in relation to successful recurrent creation in a context of intense competition, innovation and change. Our research question thus focuses our discussion on asking how strategic management enacts routines as strategies for recurrent creation 'at the edge'.

Strategy research relates strategies and routines in various ways. Routines are widely recognized as enacting an organization's development and strategies, especially in terms of contributing coherence and continuity in uncertain, changing environments (March and Simon, 1958; Penrose, 1959; Nelson and Winter, 1982). Nelson and Winter (1982) suggest exploring routines as related to strategies, and Menuhin and McGee (2001: 3) discuss routines as 'essential for progressing forward the administrative, operational and strategic activities of an organization (March and Simon, 1958; Nelson and Winter, 1982)'. A firm's long-term evolution is seen as being governed by two kinds of routines: operational routines that control its short-term behavior, and strategizing routines that enact the emergence of coherent, organization-specific patterns of actions which determine how the organization moves forward (Menuhin and McGee, 2001). Routines are seen as essential for the development of what today are discussed as an organization's resource-, competence- and knowledgebases (Teece et al., 1997; von Krogh and Grand, 2002; Salvato and Rerup, 2011). In recent years, strategy research has developed conceptualizations of strategy as related to various concepts of routines (Felin and Foss, 2004; Salvato and Rerup, 2011; Hansen and Vogel, 2010). Thus the links between routines, strategies and management have been addressed in different ways (Burgelman, 2002a, 2002b).

Researching routines in relation to strategies can be associated with identifying strategies as coherent patterns in a stream of decisions and actions (Mintzberg, 1972, 1978; Araujo and Easton, 1996). When a sequence of decisions and actions 'exhibits consistency over time, a strategy is considered to have formed' (Mintzberg, 1978: 935). Routines as strategies can thus be identified as consistent and recurring patterns of decision and action, visible in an organization's coordinated and coherent ways of operating and competing (Rumelt, 2011). We have recently seen explicit efforts to explore the impact of strategizing routines on strategy processes, inspired by the strategy-as-practice research view: 'in order to 
shape the firm's strategic path, it is important to better understand the firm's strategizing routines, to learn how to identify and characterize them, and to recognize both the potential and the limitations of their contribution to the development of the firm' (Menuhin and McGee, 2001: 6). We see strategies not as distinct from routines, but as being performed via routines - and at the same time, we recognize the coherent patterns of organizational decisions and actions that emerge from routine enactment as realized strategies (Pettigrew, 1985, 1990; Langley, 2007a). The connection between the two is not a given - strategic management relates them by enacting routines as strategies.

Strategy research explores the relationship between routines and strategies in three distinct research streams. First, the relationship is addressed in research on strategic action - including resource allocation and strategic investment (Bower and Gilbert, 2005); dynamic capabilities as embedded in operational procedures (Eisenhardt and Martin, 2000; Regner, 2008; Peng et al., 2008); knowledge creation and practices of knowing (Wenger, 1998; Tsoukas, 2005; Orlikowski, 2002); and technological innovation as related to technologies-in-use (Garud and Rappa, 1994; Orlikowski, 1992, 1996, 2007). Second, the relationship is also addressed in research on strategy processes, focusing on modes of organizing and managing strategizing processes and strategic initiatives, so studying them as routinization processes (Floyd and Wooldridge, 2000) or strategic organization (Whittington and Molloy, 2005; Langley, 2007a). Third, consideration of routines as strategies, and their routinization, is further addressed in research on strategizing activities (Jarzabkowski, 2003; Johnson et al., 2007), as an important focus in the strategy-as-practice research. In this study, we explore these research streams selectively - our intention is to show the heterogeneity of conceptual approaches and scientific debates relating strategies and routines, in particular in relation to strategies for recurrent creation 'at the edge'.

\section{RESEARCHING ORGANIZATIONAL ROUTINES IN STRATEGIC ACTION}

Strategy research describes as strategy those practices and processes aimed at attracting, generating and allocating financial and non-financial resources (Bower, 1970; Noda and Bower, 1996; Bower and Gilbert, 2005); at building competences and dynamic capabilities (Leonard-Barton, 1992; Leonard, 1995; Eisenhardt and Martin, 2000; Teece et al., 1997; Teece, 2007); at creating organizational knowledge (Nonaka, 1994; Floyd and Wooldridge, 2000); at innovating technologies (Burgelman, 1991, 1994, 
1996; Christensen, 1997), organizations (Van de Ven and Poole, 1995) and management (Birkinshaw et al., 2008; Birkinshaw, 2010). In such arguments, conceptualizing strategy in relation to routines as strategies often remains implicit, and the impact of strategic management on routines and strategies remains an unopened 'black box'.

Essentially, we see four prominent approaches in the literature to relating routines and strategies in terms of their contribution to creation, innovation and change.

First, one point of entry into this discussion is research on strategic resource attraction, generation and allocation (Bower, 1970; Bower and Gilbert, 2005). An organization's strategy is identified from the 'series of resource commitments that have been rationalized by managers at several levels of the company over many years' (Burgelman, 2002a: 454), by its record of investing financial and non-financial resources into promising initiatives, projects and opportunities over time (Burgelman, 1983a, 1983b, 1983c, 1991). A related view sees the particular impact of non-financial resources - specifically of social and human capital - as emerging from guided evolution (Lovas and Ghoshal, 2000). So resource allocation is seen as an iterative process (Noda and Bower, 1996), which is contextualized strategically and structurally, and managerially framed (Gilbert, 2005). It has been found to be 'remarkably stable even against environmental change' (Bower and Gilbert, 2005: 439), so organization-specific resource allocation patterns - identified as strategies - can be seen as routines, which systematically mobilize strategic and structural contexts as references that are enacted at different management levels.

Second, strategy is also associated with recurrent, organization-specific modes and patterns of building competences and dynamic capabilities (Teece et al., 1997; Teece, 2007). Strategy making is seen as a 'long-term adaptive organizational capability' (Burgelman and Välikangas, 2005: 60), enabling an organization to move, to remain distinct, and to thrive even under uncertainty (Peteraf, 1993). Dynamic capabilities - which are at the heart of an organization's competitiveness - have recently been related to 'identifiable and specific routines that have been the subject of extensive empirical research in their own right' (Eisenhardt and Martin, 2000: 1107). Dynamic capabilities are identified as operational routines, with the implication that '. . . the identification of specific routines in terms of their relationship to altering the resource base addresses the tautology which arises when the value of dynamic capabilities is defined in terms of their effects on performance' (ibid.: 1107). This allows us to separate the description of realized strategies from that of their underlying creation, enactment and emergence (Mintzberg and Waters, 1982, 1985; Eisenhardt and Martin, 2000; Priem and Butler, 2001), which has led to a series of more detailed 
explorations of routine dynamics and dynamic capabilities (Salvato, 2009), arguing for multilevel research on capabilities (Regner, 2003; Salvato and Rerup, 2011). But how management enacts dynamic capabilities remains an open research issue (Teece, 2007).

Third, strategy relates to the creation of organizational knowledge (Nonaka, 1994; Grant, 1996; Spender, 1996; Tsoukas and Vladimirou, 2001; Eisenhardt and Santos, 2002). Specifically, it has been argued that strategies can be studied as 'the more or less explicit articulation of the firm's theory about the basis for its past and current successes and failures. It provides a more or less shared frame of reference for the strategic actors in the organization' (Burgelman, 1983c: 1352). Seeing organizational knowledge as incorporating organization-specific concepts of performance resonates with research on organizational epistemology (Daft and Weick, 1984; Weick and Roberts, 1993; von Krogh and Roos, 1995; Tsoukas, 2005), strategic contexts (Burgelman, 1991, 1994, 2002b; Bower and Gilbert, 2005), dominant logic (Prahalad and Bettis, 1986; Bettis and Prahalad, 1995), ideology (Pettigrew, 1973, 1977) and deep structures (Gomez and Jones, 2000), all of which may define an organization's performance references, and thus help establish organization-specific views about how to assess the performance of realized strategies, strategic initiatives and operational procedures (Spender, 1989, 1996). Such knowledge is seen as being mobilized in practices of knowing (Brown and Duguid, 1991, 2001; Boland and Tenkasi, 1995; Carlile, 2002, 2004; Gherardi, 2006; Gherardi and Nicolini, 2000), in 'an ongoing and dynamic production that is recurrently enacted as actors engage the world in practice' (Feldman and Orlikowski, 2011: 1243).

Fourth, strategic action has been discussed in recent years as relating to organization-specific modes of recurrent technological innovation (Hargadon, 2003) and product innovation (Hargadon and Sutton, 1997; Salvato, 2009), and technology is seen as adding 'a dynamic character to the task of business definition, as one technology may more or less rapidly displace another over time' (Abell, 1980: 10). Innovation implies distributed processes (Barley, 1986; Van de Ven et al., 1999) in the face of uncertainties (Garud et al., 1997), encompassing the notion of moving at the frontiers of the known, the unknown, the not-yet-known and the notknowable (Bijker and Law, 1992). It has been argued that organizations rely on bricolage (Baker and Nelson, 2005), improvisation (Weick, 1998) and experimentation (Hargadon and Sutton, 1997) for agency in the face of uncertainty, and that unless executive management itself 'understands the functioning of a device and the laws that delineate its limitations, one cannot make effective judgments regarding the shaping of relevant technologies into successful products' (Burgelman et al., 2004: 4). In addition, 
it is central to address technologies-in-practice as 'recurrently produced in everyday actions that are consequential for shaping organizational outcome[s]' (Feldman and Orlikowski, 2011: 1247), so relating technological innovation to organizational routines, as well as to their socio-material qualities (Zuboff, 1988; Orlikowski and Scott, 2008; Turkle, 2011). The strategic management of technological innovation is only possible through management's involvement in this socio-material reality, and thus in innovation routines (Brown and Eisenhardt, 1997; Hargadon, 2003; Burgelman et al., 2004).

\section{RESEARCHING ROUTINIZATION IN STRATEGY PROCESSES}

In these four approaches to relating routines and strategies, as well as exploring them in relation to creation, innovation and change, it is interesting to recognize the extent to which their relationship is seen as processual and as emerging (Nonaka, 1994; Van de Ven et al., 1999; Langley, 1999). Researching the management of routines as strategies for recurrent creation 'at the edge' can benefit from research on strategy processes as organization-specific modes of enacting, managing and organizing strategic action and strategic initiatives in relation to realized strategies (Floyd and Wooldridge, 2000; Hutzschenreuter and Kleindienst, 2006). Studying how strategies and routines, realized strategies and situated activities, performance references and operative procedures are related through emergent processes, requires us - as a next step - to approach their emergence more carefully. Strategy processes are conceptualized as routinization processes underlying the creation of organization-specific repertoires of routines, and as handling the shifting and changing of such routines, or creating and establishing new ones (Floyd and Wooldridge, 2000). And such processes can also be seen as recurrently mobilizing and changing organization-specific strategic contexts and performance references (Burgelman, 2002b; Bower and Gilbert, 2005; Grand and Bartl, 2011; Grand and Ackeret, 2012).

Essentially, we see these four approaches to relating routines and references, and their managerial enactment and mobilization, as being embedded in strategy processes as routinization processes.

First, strategy processes can be studied as being formed ex ante, or as unfolding over time and being assessed ex post. Mintzberg noted that strategies could be 'intended, a priori guidelines as well as (. .) a posteriori consistencies in decisional behavior' (Mintzberg, 1978: 935), and elaborated on three types: 'intended strategies that get realized, (...) 
strategies that do not get realized, because of unrealistic expectations, misjudgments or changes during implementation, (...) realized strategies that were never intended, perhaps because no strategy was intended at the outset or because those that were got displaced along the way; these may be called "emergent strategies"” (Mintzberg, 1978: 945). Research on strategy processes suggests strategy making should be conceptualized as emerging from multiple 'processes of interpretation of new ideas, articulation of issues, elaboration of initiatives, and ratification of emergent routines' (Lechner, 2006: 56). These processes can be seen as the routinization of newly created knowledge into emergent organization-specific routines (Floyd and Wooldridge, 2000). What we have discussed as dynamic capabilities residing in operative procedures (Eisenhardt and Martin, 2000) can be re-interpreted as emergent routines which are on their way to becoming 'the organization's repertoire of operating routines' (Floyd and Wooldridge, 2000: 125), i.e., its capability base.

Second, research on strategy processes considers 'the simultaneity of induced (variation reducing) and autonomous (variation increasing) strategy processes (...) maintaining a balance between exploitation and exploration processes' (Burgelman, 2002a: 354). So strategy processes as routinization processes are characterized by stabilizing and changing organizational action patterns that enable strategic action in the face of uncertainty, but which also, at the same time, introduce new uncertainty (Langley, 2007a). Related arguments distinguish sensegiving and sensemaking (Gioia and Chittipetti, 1991; Rouleau, 2005; Rouleau and Balogun, 2011), path-dependence and path-creation (Garud and Karnoe, 2001), definition and selection (Barnett and Burgelman, 1996; Bower and Gilbert, 2005). Only by considering a close interplay between induced and autonomous strategies can we understand the generation of 'entrepreneurial activity on a continuous basis' (Burgelman, 1983c: 1358), and thus of strategy processes as routine processes promoting stability and change, continuity and innovation, and thus enabling recurrent creation 'at the edge'. So, instead of assuming organizations have routines as strategies, it is important to consider strategies as they emerge into, and are enacted as and by, organizational routines. How strategic management engages for routinization must thereby be identified as an important open research issue.

Third, these perspectives on strategy processes provide a basis for considering the impact of managerial action on strategy making and routinization processes more carefully. Strategy processes are increasingly understood as multi-layered, organizational phenomena (Bower, 1970; Pettigrew, 1985; Burgelman, 2002a; Paroutis and Pettigrew, 2007; Grand and Bartl, 2011), as dynamic, incremental interactions between 
multiple enactments of organization-specific routines and the continuous deployment of strategic contexts and performance references to observe, interpret and assess the actual performance of realized strategies, strategic initiatives and operational routines (Balogun and Johnson, 2005; Bower and Gilbert, 2005; Langley, 2010). Bower and Gilbert (2005: 453) point out that 'strategies do not develop in a vacuum and are not designed through analysis that is independent of its context and organizational setting, an observation that relates to the recent interest in strategic organization (Whittington and Molloy, 2005; Langley, 2007a; Vaara and Durand, 2012; Lavie, 2012), and echoes the insight that routine performances influence future routine performances (Feldman, 2004; Feldman and Pentland, 2008). More radically, we subscribe to the argument that 'so-called strategic "choices" are shaped by deeply embedded internalized tendencies distributed throughout the organization' (Chia and Rasche, 2010: 41), which themselves constitute an 'immanent strategy' (Chia and Holt, 2006, 2009), and considers managerial action as primarily relating to organizational routinization and thus to strategy processes (Tsoukas and Chia, 2002).

Fourth, research on strategy processes relates strategy making as routinizing to the notion of continuous change (Brown and Eisenhardt, 1997), implying that strategic change can be explored as the complex, temporal interplay of multiple actors, activities and actions (Garud and Van de Ven, 2002; Balogun and Johnson, 2004), their enactment of organizational routines and related routinization (Feldman, 2000), and their mobilization of performance references and related interpretations (Rerup and Feldman, 2011). This understanding makes stereotypical descriptions of strategic change as directed processes problematic (Melin, 1987; Pettigrew, 1990, 1992, 1997; Rüegg-Stürm, 2002, 2003). Strategy processes must rather account for change 'as emanating from an internalized modus operandi' (Ericson and Melin, 2010: 326), as the inevitable 'drift' of any strategy process as it unfolds over time (Mintzberg and Waters, 1985, 1990; Mintzberg and McHugh, 1985; Chia and Holt, 2009). At the same time, recent research has argued that - in many industries - it is strategic to approach change as continuous (Brown and Eisenhardt, 1997), and thus identify recurrent creation and change under uncertainty as a successful strategy for competing at those industries' frontiers (Hargadon, 2003). In particular, research finds companies deliberately making room for improvisation, using what could be called 'semistructures', relying on a wide variety of 'low-cost probes into the future' (Brown and Eisenhardt, 1997: 1), allowing for systematic experimentation, time-paced coordination and sequenced de- and re-routinization (Hargadon and Sutton, 1997; Salvato, 2009), so making history a highly dynamic context, 'as a living 
tradition in the sense that history belongs to present future-oriented strategic activities' (Ericson and Melin, 2010: 342).

\section{RESEARCHING ROUTINES AND ROUTINIZATION IN STRATEGIZING ACTIVITIES}

In these four routes scholars have taken to relate strategy processes and routine processes, we recognize the extent to which these processes are implicitly seen as managerially enacted, but do not explicitly address managerial action and management practices. Researching routines as strategies, as enacted in organizational activities and as emerging from routinization processes, builds on a recent research stream focusing on strategies as being related to strategizing activities, micro-strategies and strategy-as-practice (Hendry, 2000; Jarzabkowski, 2005; Johnson et al., 2003; Whittington et al., 2003; Golsorkhi et al., 2010). Strategy-as-practice research focuses on understanding how strategy serves to constrain and enable the actions taken, and how particular strategic consequences emerge: 'strategy as practice shifts the analytic focus to how strategy is constructed rather than how firms change, to understand the myriad of interactions through which strategy unfolds over time, each of which contains the scope and potential for either stability or change' (Jarzabkowski, 2005: 5). Research on strategizing in a practice perspective complements our discussion of organizational routines as related to realized strategies, as well as exploring the routinization inherent in strategy processes, by explicitly addressing the importance of managerial and non-managerial action in their enactment.

We see four approaches to relate routines and strategies to strategizing activities, linked to and beyond managerial action, as exploring agency in strategy as something not automatically given.

First, research on strategizing activities focuses on strategies as enacted in multiple activities involving different actors. Strategy process research has already irrevocably opened up the 'black box' of the organization (Bower, 1970; Pettigrew, 1973, 1977, 1987; Melin and Hellgren, 1994; Burgelman, 2002a; Burgelman and Grove, 2007) to describe the multiple and heterogeneous activities and actors involved in strategy formation and their dynamic interactions (Barley and Tolbert, 1997; Samra-Fredericks, 2003). Indeed, strategic management and strategy research have been criticized as 'reminiscent of the early anthropologists' accounts of tribal customs based on conversations with local chiefs on colonial verandas (...) if we want to grasp the micro activity of practice, we shall need to get off our verandas' (Johnson et al., 2003: 11). This 
requires an intimate comprehension of the local proficiencies required to perform everyday strategizing practices skillfully, directing attention to 'the minutiae of tacit and almost imperceptible interventions' (Chia and Rasche, 2010: 44). Research on routines as strategies enacted as situated activities and by operational procedures is thus complemented by addressing strategizing activities as being inherent in organizational participants' situated activities (Johnson et al., 2007). Chia and Holt (2009: 129) suggest considering individual activities as leading to a personal 'style of engagement: a generic strategy that expresses itself in the many different activities and thoughts that make up an agent's life'. This requires investigating the inherited background from which practitioners engage in practical coping, 'exploring how aspects of the inherited background are brought to explicit awareness' (Tsoukas, 2010: 60).

Second, research on strategy processes has 'populated the arena of strategy development with human beings' (Johnson et al., 2003: 11), but advancing this perspective calls for a dedicated theory of social action within the strategy context, which has been identified as a call for a creative theory of strategy (Tsoukas and Knudsen, 2002) which includes human action in strategy research, based on insights from sociological action theory (Joas, 1992), practice theory (Pickering, 1995; Schatzki et al., 2001; Reckwitz, 2002) and the cognitive sciences (Clancey, 1997; Clark, 1997; Elsbach et al., 2005). We advocate exploring human action as creative (Joas, 1992; Tsoukas and Knudsen, 2002), projective (Boutinet, 1990; Groys, 1991), tactical (de Certeau, 1984), subjective (Taylor, 1989; Bruner, 1990) and embodied (Pfeifer and Bongard, 2007), considering strategizing activities 'as an undertaking of disclosure in which the future and past are felt in the unfurling present (...) strategy is also about a field of significance being opened up, opportunities being discovered, and this potentiality is experienced on an intensive rather than just extensive field' (Chia and Holt, 2009: 132). At the same time, a creative theory of action emphasizes its social embeddedness, 'in terms of a sociality of inertia: cultural transmission, socialization, institutionalization, disciplinary regimes, ensure a regularity of behavior that makes [it] more or less socially predictable (. . .) most human action takes place through this form of thoughtless practical coping' (Chia and Holt, 2009: 130). These arguments relate research on human action in strategizing to the analysis of organizational routines.

Third, strategizing activities are also explored as being related to artifacts, a view that illustrates the generative qualities of strategy concepts and tools, references and techniques (Hodgkinson et al., 2006; Spee and Jarzabkowski, 2009), and reveals the material aspect of strategies as displayed, visualized, exchanged and communicated, for example, in PowerPoint presentations (Yates and Orlikowski, 2007; Kaplan, 2011) or 
strategy visualizations (Bürgi et al., 2005; Giraudeau, 2008; Eppler and Platts, 2009). This echoes practice theory in describing action as being 'equipped' (Thévenot, 2001a, 2002), meaning that 'mediation (the use of media to communicate and interact) and technologization (the use of conceptual tools, technologies and other means) (...) are fundamental features of contemporary organizations' (Golsorkhi et al., 2010: 14). More radically, it has been argued that strategic management can itself be seen as a technology: as 'a techné, management is the same age as the other major areas of knowledge that underlie today's high-tech industries' (Drucker, 1985: 11). Strategizing practices and routines are structured through particular concepts and tools, formats and settings (Johnson et al., 2007; Carlile, 2002), and are embedded in technological systems.

Fourth, this raises the issue of agency (Emirbayers and Mische, 1998), including the strategic agency of management, but also of organizational actors in general and of how they enact routines as strategies. 'Process research has been reluctant to query the role of managerial agency' (Pettigrew, 1985, quoted in Johnson et al., 2003: 12). While some studies show that managers are central to strategizing (Hellgren and Melin, 1993), and that actors at the periphery have crucial effects (Johnson and Huff, 1998), further research is needed to understand how they actually make a difference (Mintzberg, 2009; Tengblad, 2012). In addition, it has been argued that strategizing activities and managerial action can 'be captured in wider belief systems and technologies that constrain their possibilities for action' (Johnson et al., 2003: 12), which makes it important to explore the extent to which managerial and non-managerial action is constrained or enabled by organizational routines, practices and references. Strategy-as-practice research argues that 'there are still few analyses that specify the ways in which organizational actors are at the same time constrained and enabled by prevailing practices' (Golsorkhi et al., 2010: 14). Thus, managerial action, and human action more generally, are seen as de-centered, while the importance of organization-specific repertoires of routines, practices and references structuring managerial and non-managerial action is emphasized (Barley and Tolbert, 1997; Jarzabkowski, 2008).

\section{DISCUSSION: PERSPECTIVES FOR RESEARCHING ROUTINES AS STRATEGIES}

Approaching the theoretical conceptualization and empirical description of strategy and strategic management from a routine perspective makes for a research stance, which relates dispersed contributions on the basis 


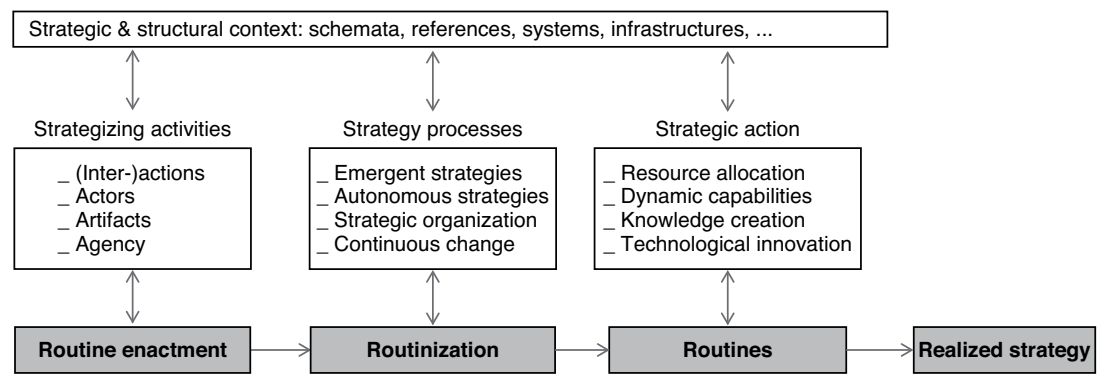

Figure 1.1 Routines as strategies: overview and interdependencies

of a particular research focus. Many contributions to strategy research refer to organizational routines for understanding strategic action, strategy processes and strategizing activities (for an overview, see Figure 1.1). Approaching strategies as routines provides us with another perspective, bringing to center stage certain aspects and patterns of strategy making that are otherwise ignored or addressed only incompletely, and supports the intention of strategy-as-practice research to 'mindfully cultivating an alternative perspective that can shed light on the strategy phenomenon, (opening) new lines of sight on strategy making and new possibilities of theorizing strategy' (Golden-Biddle and Azuma, 2010: 88).

Our approach complements strategy-as-practice research by addressing some open issues in that stream - and more specifically, by focusing on routines as a particular type of practice (Feldman and Orlikowski, 2011). We suggest researching routines as strategies has the potential to address their theoretical conceptualization and empirical description in areas such as: strategy making as embedded in a web of practices (Vaara and Whittington, 2012); agency in strategizing (Golsorkhi et al., 2010); strategy beyond the micro-macro divide (Felin and Foss, 2005; Johnson et al., 2007); processes of emergence in strategy making (Vaara and Whittington, 2012); and practices of thinking (Melin, 2007).

Based on this literature review, we identify eight areas where we believe researching routines in relation to strategies can benefit wider research efforts.

First, researching routines as strategies involves getting away from taken-for-granted concepts of strategy, focusing on empirically observable patterns of decisions and actions. Viewing strategies as related to routines for enacting recurrent creation implies that whether and to what extent an organization can be described by particular strategies are empirical questions (Mintzberg, 1978; Mintzberg and Waters, 1985, 1990; Pettigrew, 1985). A firm's strategies should not be identified simply as 
what managers announce them to be, but characterized by what is actually done and becomes visible as its recurrent organizational pattern of action. This resonates with research exploring organizations that operate without codified, formulated or documented strategies (Inkpen and Choudhury, 1995; MacCrimmon, 1993), and with studying strategies as empirically embedded in strategizing activities, independent of whether or not they are formally seen or explicitly framed as such (Johnson et al., 2003; Chia and MacKay, 2007; Chia and Holt, 2009). So it makes sense to expect an organization to have several action patterns as its strategies, and to explore how far, how and why they display recurring patterns, as well as how and why they change over time.

Second, we distinguish various types of routines in relation to strategy as being intimately entangled. Routines are implied in the attraction, generation and allocation of financial and non-financial resources, and at the same time relate to the organization's strategic and structural context. Dynamic capabilities are embedded in operative procedures that make an organization distinct (Eisenhardt and Martin, 2000), and are assessed in terms of their contribution to its competitive success. Organizational knowledge emerges from situated activities of knowing (Cook and Brown, 1999), while at the same time refers to organization-specific references, contexts, practices and routines, which are mobilized as resources in these situated activities (Hardy et al., 2000). Technological innovation relates to technologies-in-use, implying close interplay between artifacts and practices, technical systems and organizational routines, which are describable as socio-material processes (Orlikowski and Scott, 2008). It is important to distinguish routines implied in resource allocation and capability building, knowledge creation and technological innovation, and thus also in strategy making and strategic management itself (Menuhin and McGee, 2001).

Third, the literature distinguishes between different ways in which routines relate to strategy: they have been related to operational procedures (Eisenhardt and Martin, 2000), to organizational practices (Vaara and Whittington, 2012), to resources (Bower and Gilbert, 2005), to embodied experiences and knowledge (Tsoukas, 2005), and to technologies (Orlikowski, 2000). Thus researching from the strategy-as-practice perspective involves addressing explicitly the dynamic interplay between situated action and strategizing activities, the mobilization of strategizing routines and strategic practices, the roles of multiple strategy-related references and artifacts as strategy making resources and how strategy processes embody experiences and modes of knowing (Tsoukas and Knudsen, 2002; Gomez and Bouty, 2011). Researching routines as strategies in this perspective requires re-conceptualizing such dynamics on a sound 
theoretical basis. As we discuss in Chapter 2, research on routine dynamics (Feldman and Orlikowski, 2011) provides a promising perspective for advancing our conceptualization and description of strategies as related to routines (Salvato and Rerup, 2011), which complements and deepens insights from strategy-as-practice research.

Fourth, we recognize the importance of routines for strategy processes, explaining how organizational activities, embedded in operational procedures and organizational routines, relate to realized strategies as emergent patterns of organizational action (Mintzberg and Waters, 1985; Bower and Gilbert, 2005). We also recognize the extent to which processes and practices of resource allocation, agenda setting, initiative formation, decision making and performance assessment are mediated by organizationspecific routines (Floyd and Wooldridge, 2000; Burgelman, 2002a, 2002b). We further understand how routine enactment relates to mobilizing strategic and structural contexts (Burgelman, 1991, 1994, 1996; Bower and Gilbert, 2005), organization-specific ideologies (Pettigrew, 1973, 1977) or references (Gomez, 1994, 1996; Gomez and Jones, 2000). It is through their mobilization - in relation to routine enactments and managerial actions that recurrent patterns of action and decision emerge, a process which we describe as realized strategies emerging through routinization (Gomez and Jones, 2000; Floyd and Wooldridge, 2000). Advancing our view on this interplay requires a theoretically sound conceptualization of routine dynamics.

Fifth, understanding routines as strategies in this perspective implies approaching routines as being embedded in an organization's particular context, which can be identified as its taken-for-granted references. Processes, practices and routines are 'constrained by contexts and shape contexts, either in the direction of preserving or altering them' (Pettigrew, 1990: 270); an interpretation that implies contextualization is inherent in any mobilization of strategic references or organizational routine enactment. Context has been described 'not just as a barrier to action, but as essentially involved in its production' (Giddens, 1979, quoted in Pettigrew, 1990: 270), implying that structures and contexts are mobilized by actors and organizations 'as they seek to obtain outcomes important to them' (Pettigrew, 1990: 270). This view suggests a dynamic understanding of context, not as something automatically given, but as being enacted as taken-for-granted. Researching routines as strategies thus calls for us to study routines 'that constitute (and contextualize) strategy and strategizing in a given setting' (Golsorkhi et al., 2010: 13). Contextualization is essential for enabling organizational action, while protecting organization-specific routines and references - which might otherwise become contested - as unquestioned (Gomez and Jones, 2000). 
Sixth, we recognize the importance of understanding how routines as strategies relate to stability and change, to continuity and renewal. This resonates with our interest in describing strategies as patterns of decisions and actions, including those 'that were intended and those that were realized despite intentions' (Mintzberg, 1978: 934). This understanding also builds on a concept of strategy as 'how an organization will move forward' (Rumelt, 2011: 6), emphasizing the dynamic relation between realized, intended and emergent strategies (Mintzberg and Waters, 1985). Studying strategies as emerging from routinization requires that we describe carefully how they 'change, act and evolve over time (perhaps best expressed by Andrew Pettigrew (1992: 11) as catching "reality in flight") or, adopting a more radical process ontology, how such "things" come to be constituted, reproduced, adapted and defined through ongoing processes (nicely expressed in Tsoukas and Chia's (2002) reference to "organizational becoming")' (Langley, 2007a: 271), through processes of continuous change (Eisenhardt and Martin, 2000) and strategic 'drift' (Chia and Holt, 2009). We see how recurrent creation (Hargadon and Sutton, 1997; Brown and Eisenhardt, 1997; Salvato, 2009) relates just as much to routinization and to change that emerges from routines.

Seventh, routines are important for understanding how managerial and non-managerial actions relate to strategizing. On the one hand, strategizing activities must be approached as highly situated and improvisational, and as involving subjective and personal intentions, agendas and beliefs (Samra-Fredericks, 2003). On the other, managerial and non-managerial actions continuously enact organizational routines and practices, as well as multiple references and contexts for ensuring agency (Rerup and Feldman, 2011). Researching strategizing activities as enacting routines teaches us to distinguish the two carefully, and so to understand how intimately they can be intertwined. However, emphasizing the many situated activities and routine enactments involved in strategy making is increasingly seen as implying the challenging question of how such activities can be identified as 'strategic' (Paroutis and Pettigrew, 2007), and thus whether and how strategies can be researched in terms of how they emerge as realized and organizationally relevant. This requires considering explicitly how particular strategy concepts, strategic contexts and performance references are referred to and mobilized as relevant for and as related to these situated activities.

Eighth, a careful exploration of what is understood by performance becomes important (Thomas et al., 1993; Eisenhardt et al., 2010). We join March and Sutton (1997) in their critical assessment of performance as a dependent variable, and their opinion that 'the ways in which performance advantages are competitively unstable, the causal complexity 
surrounding performance, and the limitations of using data based on retrospective recall' (March and Sutton, 1997: 698) make any taken-forgranted concept of performance problematic. In view of our discussion of routines as related to strategies, we recognize that we must distinguish carefully between different uses of the term 'performance': we can register the enactment - 'the performance' - of a particular routine or strategy, or we can assess the actual 'performance' of routines, practices and procedures, in terms of how successfully they are enacted, how well they are performed. Thereby, the assessment of performance can never be independent of the organization-specific strategic context and the particular performance references mobilized for its assessment, and will always relate to performance expectations, or to how performance is realized by competing organizations. As a consequence, strategic management inherently involves the mobilization of performance references in measuring the success of enactments of particular situations and opportunities, routines and procedures (Grand and Bartl, 2011).

\section{CONCLUSION: ADVANCING THE RESEARCH OF ROUTINES AS STRATEGIES}

In sum, approaching the theoretical conceptualization and empirical description of strategy and strategic management from a routine perspective allows us to identify a series of promising research areas while at the same time complementing the research agenda for further advancing strategyas-practice research (Whittington, 2006; Langley, 2007b; Melin, 2007; Golsorkhi et al., 2010; Vaara and Whittington, 2012). It is clearly important for our purpose to explore in more detail how routine dynamics can be conceptualized: this will be the focus of Chapter 2. This exploration benefits from more than a decade of systematic research on organizational routines as generative systems (Pentland and Rueter, 1994; Feldman, 2000, 2003; Feldman and Pentland, 2003, 2005, 2008; Feldman and Orlikowski, 2011). We also recognize the importance of exploring in more detail how routine enactment relates to managerial and non-managerial action (Johnson et al., 2003; Mintzberg, 2009; Tengblad, 2012), as well as how we can make sense of organizational routines as being strategically enacted by management: this will be the focus of Chapter 3. This effort benefits from theoretical contributions that have advanced what has been labeled the 'practice turn' (Pickering, 1995; Schatzki, 2001; Schatzki et al., 2001; Reckwitz, 2002) - in particular the pragmatist theory of creative action (de Certeau, 1984; Joas, 1992, 1997), actor network theory (Callon, 1986; Latour, 2005, 2012) and convention theory (Boltanski and Thévenot, 1991; Thévenot, 2001a, 2006). 
So we can conclude that researching strategies in a routine perspective advances and focuses strategy research in the following ways.

First, in terms of the conceptual perspectives and theoretical elements discussed in Chapter 1, we can sketch a simple model of the relationship(s) between realized strategies as recurrent patterns of organizational decisions and actions, organizational routines as generative systems, performance references as strategic contexts, and managerial and non-managerial actions (see Figure 1.2). This perspective allows us to research strategic management and strategy making by conveying 'the depth, variety and fluidity of strategic activities, judgments and consequences that refuse to be contained by a solitary case or definitive end point' (Chia and Holt, 2009: 119). The model shows how the 'what' of strategies and routines and the 'how' of their performances are intertwined, and how organizational routines and their dynamic enactment relate to explicit and implicit, internal and external reference criteria and strategic contexts, which are only temporarily stable and may always be contested (Callon, 1986; Gomez, 1996; Gomez and Jones, 2000). The model indicates how important it is to consider explicitly how managerial and non-managerial action enacts routines and mobilizes strategic references for judging, assessing and justifying emergent patterns of decisions and actions in their performances (Thévenot, 2001a, 2006; Karpik, 2007).

Second, it is important to note that such a simplified visual display is - to an extent - misleading, since the temporal dynamics of such intertwined elements are not illustrated. Any further theoretical conceptualization or empirical description would imply approaching strategies as 'continuously clarified through each iterative action and adjustment and not through any predetermined agenda' (Chia and Holt, 2009: 159), which would require going beyond understanding strategies, routines and references as given entities. Whether, how and why specific recurrent patterns of actions and decisions emerge cannot be deduced from underlying entities - they must be understood as emerging from their multiple enactment and mobilization, which requires 'a sense of the positivity of incompleteness: one is under way, and in being under way, the ends of one's actions emerge as one goes along (. . .) it is these locally initiated spontaneous responses, the ad hoc making do's, that often generate longer-term sustainable outcomes' (Chia and Holt, 2009: 186). So this model must be interpreted with a consciousness of the dynamic interplay invisible in its illustration.

Third, our view on strategies and strategic management considered from a routine perspective has consequences for how we discuss strategic management. Seeing strategy as related to the mobilization and enactment of organizational routines implies that 'management should be alert to 


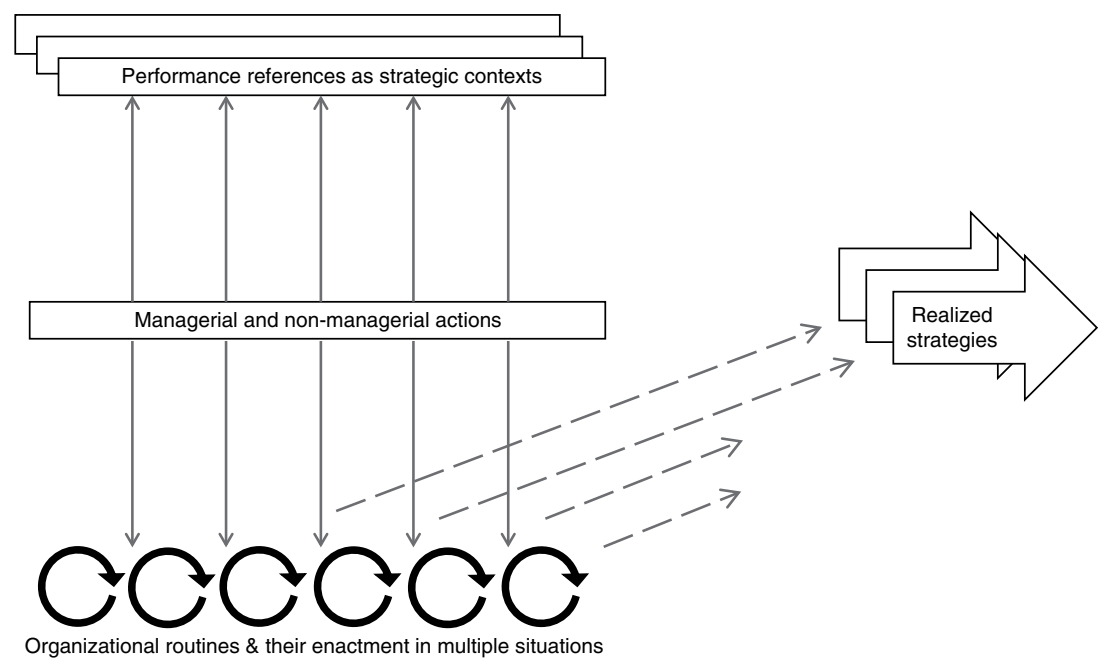

Figure 1.2 Basic model: strategies, references, routines and management

proposals that emerge deep in the organization' (Burgelman, 1988: 84), recognize inertial forces, and 'rather than denying (. . .), take action that alleviates or redirects them' (Barnett and Burgelman, 1996: 10). Strategic management is thus not only proactive and creative, but also indirect (Jullien, 2005), implying 'containment and the capacity to endure rather than the capacity for active intervention' (Chia and Holt, 2009: 211). So explicitly questioning the concept of management inherent in strategy research resonates with strategy-as-practice research itself, the first generation of which has focused on understanding strategizing activities beyond (executive) management (Johnson et al., 2003; Jarzabkowski et al., 2007), while the second generation now emphasizes the importance of a sound theoretical basis for relating the study of strategizing activities to organizational processes (Jarzabkowski and Spee, 2009; Golsorkhi et al., 2010), including an explicit re-conceptualization of management (Tengblad, 2012; Whittington, 2012).

Fourth, our view on strategies and strategic management from a routine perspective implies that companies can be both researched and managed as competing via their organization-specific routines, managerially enacted as strategies, which meet specific performance references. This resonates with our particular interest in understanding how companies recurrently create 'at the edge' to compete successfully in dynamic markets. Based on two case studies (given as Chapter 4 and 5) we explore this perspective empirically, by studying how an haute couture textile company competes 
by recurrently creating new fabrics, collections and technologies to stay at the frontier of the highly dynamic and uncertain fashion industry; and how a software engineering company competes by recurrently realizing new projects to stay at the frontier of the fast-changing software industry, while at the same time innovating its own approach to organization and management. 